Article Type: Original Article

\title{
TFM classification and Staging of oral submucous fibrosis:
}

\section{A new proposal}

\author{
Gururaj Arakeri, ${ }^{1,2}$ Deepak Thomas, ${ }^{3}$ Abdulsalam S. Aljabab, ${ }^{1,4}$ Santosh Hunasgi, ${ }^{5}$ \\ Kirthi Kumar Rai, ${ }^{6}$ Beverley Hale, ${ }^{7}$ Felipe Paiva Fonseca, ${ }^{8}$ Ricardo Santiago Gomez, \\ Siavash Rahimi, ${ }^{9,10}$ M.A.W. Merkx, ${ }^{2}$ Peter A Brennan ${ }^{3}$
}

${ }^{1}$ Department of Oral and Maxillofacial Surgery, King Fahad Medical City, Riyadh, Saudi Arabia

${ }^{2}$ Department of Oral and Maxillofacial Surgery, Radboud University Medical Centre, Nijmegen, The Netherlands

${ }^{3}$ Department of Oral \& Maxillofacial Surgery, Queen Alexandra Hospital, Cosham, Portsmouth, UK

${ }^{4}$ Department of Dentistry, Faculty of Dentistry, King Saud University, Riyadh, Saudi Arabia

${ }^{5}$ Department of Oral and Maxillofacial Surgery, Navodaya Dental College and Hospital,

Raichur, Karnataka, India

${ }^{6}$ Department of Oral and Maxillofacial Surgery, Bapuji Dental College and Hospital,

Davangere, Karnataka, India

${ }^{7}$ Department of Learning and Teaching, University of Chichester, College Lane, Chichester, West Sussex PO19 6PE, UK

${ }^{8}$ Department of Oral Surgery and Pathology, School of Dentistry, Universidade Federal de Minas Gerais, Belo Horizonte, Brazil

${ }^{9}$ Pathology Centre-Histopathology, Queen Alexandra Hospital, Portsmouth, UK

${ }^{10}$ School of Pharmacy and Biomedical Science, University of Portsmouth, Portsmouth, UK

\section{Correspondence:}

Dr Gururaj Arakeri MDS, PhD

Department of Oral and Maxillofacial Surgery,

King Fahad Medical City, Riyadh,

Saudi Arabia

gururaj.arakeri@gmail.com

This article has been accepted for publication and undergone full peer review but has not been through the copyediting, typesetting, pagination and proofreading process, which may lead to differences between this version and the Version of Record. Please cite this article as doi: 10.1111 jop. 12689

This article is protected by copyright. All rights reserved. 


\section{ABSTRACT:}

Background: We have evaluated the rationale of existing grading and staging schemes of oral submucous fibrosis (OSMF) based on how they are categorized. A novel classification and staging scheme is proposed.

Methods: 300 OSMF patients were evaluated for agreement between functional, clinical and histopathological staging. Bilateral biopsies were assessed in 25 patients to evaluate for any differences in histopathological staging of OSMF in the same mouth. Extent of clinician agreement for categorized staging data was evaluated using Cohen's weighted Kappa analysis. Cross-tabulation was performed on categorical grading data to understand the intercorrelation and the unweighted kappa analysis was used to assess the bilateral grades agreement. Probabilities of less than 0.05 were considered significant. Data were analyzed using SPSS Statistics (version 25.0, IBM, USA).

Results: A low agreement was found between all the stages depicting the independent nature of trismus, clinical features and histopathological components $(K=0.312,0.167,0.152)$ in OSMF. Following analysis, a three component classification schemes (TFM classification) was developed that describes the severity of each independently, grouping them using a novel three tier staging scheme as a guide to the treatment plan.

Conclusion: The proposed classification and staging could be useful for effective communication, categorization and, recording data and prognosis, and for guiding treatment plans. Furthermore the classification considers OSMF malignant transformation in detail.

Key words: Oral Submucous fibrosis; Potentially malignant disorder; TFM Classification; TFM Staging; Malignant transformation

This article is protected by copyright. All rights reserved. 


\section{INTRODUCTION:}

Oral submucous fibrosis (OSMF) is a chronic, debilitating condition of the oral cavity causing progressive scarring of the oral mucosa. ${ }^{1}$ There has been recent discussion regarding the classification and staging of OSMF. ${ }^{2,3}$ Though no individual clinical variants of OSMF exist, several classification schemes have been described in the literature. ${ }^{2-18}$ In reality, existing classification schemes are essentially staging and grading systems of OSMF rather than being true classifications. The current schemes of OSMF stage and grade are based solely on a diagnosis of the predominant lesions instead of potential changes in the entire oral cavity. The simple subdivision of the severity of OSMF into different stages should perhaps not form the principal basis for classification.

The most important factors in managing OSMF are the functional and clinical staging of the disease with information on any malignant transformation. ${ }^{19}$ Once the degree of severity of OSMF is established, histology guides appropriate patient management. ${ }^{2}$ However, despite years of research, there is still no staging or grading scheme universally accepted and employed by clinicians, pathologists and surgeons. ${ }^{2}$ Since the original proposal of the histological grading and clinical staging system by Pindborg et al. ${ }^{8,9}$ there has been a wealth of information published on both clinical and histopathological features of OSMF. Surely it is now time to rethink the way in which the OSMF patients are evaluated and classified.

The purpose of this paper is to evaluate the rationale of existing grading and staging schemes of oral submucous fibrosis (OSMF) based on which they are categorized. A novel classification, staging and grading scheme is proposed which takes into consideration independent functional and clinical findings, together with information on any malignant transformation of OSMF.

This article is protected by copyright. All rights reserved. 


\section{MATERIALS ANS METHODS}

Following Ethical Committee Approval from the institutional review board, the study was conducted in Shahapur of the Yadgir district, Hyderabad-Karnataka region, India. Written consent was obtained from all patients.

300 patients with clinically diagnosed OSMF were randomly recruited for the study. All those selected had a 'WHO performance status and comorbidity score' ${ }^{20,21}$ of either 0 or 1. All OSMF patients recruited chewed gutkha (crushed areca nut, tobacco, catechu, paraffin wax, slaked lime and sweet or savoury fillings) or areca nut.

The study was conducted in three stages.

Stage 1: The clinicopathological classification system currently the most widely accepted by Khanna and Andrade ${ }^{19}$ was analysed to evaluate concordance between function and clinical presentation. Functional, clinical and histopathological features were analysed separately for convenience and recorded as shown in Tables 1 and 2. To ease the comparison, the subset features of stage $4 \mathrm{a}$ and $4 \mathrm{~b}$ are considered together as a single group.

All patients were examined to record functional and clinical stage of OSMF and the results documented by one of the authors (GA). To assess the correlation between the staging and number of affected surfaces, we divided the oral mucosal surfaces into 6 sites: right and left buccal mucosa, tongue, lip, floor of mouth, and oropharynx. The affected surfaces were documented in each patient and tabulated.

Stage 2: From the 300 patients recruited to this study, those with bilateral buccal OSMF were listed separately and 50 patients were randomly selected. $3 / 50$ patients could not be categorized on grading scores due to severe trismus, and therefore were not included, so a total of 47 patients were included in the analysis. All 47 patients underwent incisional biopsy 
of the most prominent buccal lesion and the disease was histologically graded by one of the authors ( $\mathrm{SH}$ ) using histopathological features proposed by Khanna and Andrade ${ }^{19}$ (Table 2). The grades were documented and tabulated to discern a correlation between staging and histological grading.

Stage 3: 25 patients were randomly selected from the 47 patients with bilateral buccal OSMF included as above. All 25 patients underwent a further biopsy of the contra lateral OSMF buccal mucosa and were histologically graded by the same pathologist. All grades were tabulated to evaluate any differences with bilateral grading.

\section{Statistical analysis}

Nominal (categorical) data was analysed and assessed for agreement and correlation. The extent of agreement between categorized staging data was done using Cohens weighted Kappa analysis. McHugh's guidelines ${ }^{22}$ were used to interpret kappa in the study. The correlation between staging (clinical and functional) and the number of affected surfaces was performed using Spearman's rank correlation coefficient. Cross tabulation was done on categorical grading data to understand inter-correlation and unweighted kappa analysis was used to assess bilateral grades agreement. Probabilities of less than 0.05 were considered significant. SPSS Statistics for Windows (version 25.0, IBM Corp, Armonk, USA) was used for data analysis.

\section{RESULTS}

The mean age of the 300 patients recruited to this study was 22.0 years ( $\mathrm{SD}+/-8$ years).

Stage 1: All 300 patients recruited were assessed for the extent of OSMF. Agreement between functional and clinical staging was assessed using Cohens weighted Kappa. The correlation between staging (clinical and functional) and number of affected surfaces was assessed using Spearman's rank correlation coefficient.

This article is protected by copyright. All rights reserved. 
The agreement between functional and clinical staging was relatively low $(\mathrm{k}=0.312)$. The correlations between the clinical staging and number of affected surfaces (Spearman's rho = 0.152 ) and functional staging and number of affected surfaces (Spearman's rho $=-0.135$ ) had no statistical or clinically significant relationship (effect size $=0.144$ ).

Stage 2: From the population sample of 300, a random sample of 47 patients who had mucosal biopsies was analyzed for agreement between staging (clinical and functional) and histopathological grading.

Cohen's weighted kappa $(\mathrm{k}=0.167)$ quantified the extent of complete or near agreement between clinical staging and grading data, with a weighted agreement of $17 \%$, indicating a poor agreement between clinical staging and histopathological grading.

Cohen's weighted kappa $(\mathrm{k}=0.152)$ also demonstrated a similar level of weighted agreement between functional staging and histological grading depicting a low agreement between these two categories.

Stage 3: Kappa analysis was used to assess potential agreement between bilateral histopathology grading of OSMF, in the 25 patients who had bilateral buccal mucosa biopsies. The unweighted kappa value of $-0.478(\mathrm{p}<.001)$ indicated that there was very little chance of agreement between the two grading categories. To further understand the correlation between the bilateral grading, cross-tabulation was performed on categorical data (Table 3). The tabulation showed no complete agreement between the bilateral histopathological grades in any of the 25 patients who had bilateral buccal mucosal biopsies (the highlighted diagonal shows zero throughout table 2).

This article is protected by copyright. All rights reserved. 


\section{DISCUSSION}

Several staging systems based on different aspects of OSMF have been suggested to aid classification. ${ }^{2-19}$ Existing staging systems can be broadly categorized into clinical staging, histological staging, and clinicopathological Staging. The earliest staging by Pindborg and Sirsat $^{9}$ in 1966 was based on histopathological features and was updated in 2005 by Utsunomiya et al. ${ }^{10}$ Wahi et al. ${ }^{11}$ presented the first clinical staging (of 3 groups) based on symptoms, and subsequently several others have been proposed. ${ }^{2-18}$ Khanna and Andrade combined both histopathological and clinical features of the disease, and developed a staging in the form of groups to aid surgical management. ${ }^{19}$ Another has proposed a grading system which incorporates any incidence of other potentially malignant disorders (including dysplasia) with traditional clinical findings. Others have categorized OSMF into two staging systems; clinical and functional. ${ }^{2}$ Clinical includes OSMF symptoms and any associated premalignant disorders, while inter-incisal opening was separately recorded as functional staging.

However, significant confusion still exists due to the indiscriminate use of functional, clinical and histological components of OSMF in the current classification schemes. ${ }^{2}$ There is no consensus for individual or combined use of these parameters to stage or classify OSMF. ${ }^{2}$ Furthermore, existing classification schemes represent only the most prominent lesions instead of the potential changes in the rest of the oral cavity. ${ }^{2-19}$ Since OSMF has no clear and definable borders, it may not be appropriate to use the predominant lesion to indicate the complexity of entire OSMF behaviour in the oral mucosa. Therefore, inclusion of the entire oral cavity in a holistic approach rather than solely an individual lesion seems reasonable.

We investigated the agreement between the three main elements of current staging (functional, clinical and histological) and histological grading with the aim of possibly using

This article is protected by copyright. All rights reserved. 
them in combination. We also evaluated the agreement of involvement of oral mucosal surfaces with different stages of the diseases.

The results of this study clearly show no agreement between functional and clinical staging ( $\mathrm{k}$ $=0.312$ ) indicating mouth opening is independent of clinical features. Hence there is always a greater chance of repetition or difference of clinical symptoms of one stage with functional symptoms of another stage (Figure 1A). In some instances, the additional trismus in OSMF might be because of impingement of the upper third molar on the coronoid process (Figure 1B). In such cases, removal of the third molar might significantly improve mouth opening. The existing staging schemes seem not to consider trismus due to other factors and may lead to false staging. ${ }^{13-19}$ In severe trismus, it is usually not possible to assess clinical stage due to difficulties with visualisation. Therefore, staging only based on functional components may not provide all the clinical details.

We found no significant correlation between stages and the number of mucosal surfaces affected, suggesting present staging systems do not take into account the number and severity of surfaces involved. After analysing the histopathology of 47 random patients with their clinical and functional stages, we found no agreement between clinical staging $(\mathrm{k}=0.167)$, functional staging $(\mathrm{k}=0.152)$, and histological grade (weighted agreement less than 17\%).

Since OSMF malignant transformation is known to be independent of stage and site in the affected oral cavity (Figure 1C), ${ }^{23-27}$ grouping OSMF patients with malignant transformation in late stages may result in losing vital data with prognostic value. Hence the validity of any clinicopathological classification and its usefulness in treatment planning remains questionable.

This article is protected by copyright. All rights reserved. 
For the first time to our knowledge, we analyzed bilateral buccal mucosa biopsies to further evaluate the uniformity of histological grade in multiple oral sites, finding grading agreement between bilateral biopsy sites was low $(\mathrm{k}=-0.478)$. This finding suggests there may be multiple grades of OSMF throughout the oral mucosa. Existing grading systems signify the status of only a prominent lesion chosen by the clinician. ${ }^{14-19}$

Malignant transformation in OSMF can occur anywhere in the oral cavity. ${ }^{23,25}$ Unlike oral SCC, OMFS can be diffuse and heterogeneous and be present at different anatomical mucosal surfaces and with different behaviours. ${ }^{28,29}$ It is difficult to conclude that the most prominent OSMF lesion represents the status of the entire oral cavity. ${ }^{28}$ Thus histopathological grading only has a role in understanding the progress of OSMF, but its usefulness in monitoring disease progression and overall treatment planning remains uncertain. ${ }^{29}$ Biopsy and histopathological grading are of course important in the diagnosis of suspected lesions. ${ }^{26}$

A systematic classification scheme which utilises all the clinical, functional and histological data independently might be helpful and practical for investigating the OSMF complexity. ${ }^{2} \mathrm{~A}$ comprehensive staging system amassing all the data of the classification would also be beneficial to guide treatment plan.

We have developed a three component classification scheme (termed TFM classification) which independently assesses all three main OSMF components: trismus, fibrosis, and malignant transformation. The use of terms clinical and functional together to categorise OSMF seems inappropriate as trismus can also be a clinical feature. Hence trismus and fibrosis were used separately to indicate the severity of the disease. In the third component, 
we combined the suspicious clinical structural changes with histopathological features to aid in treatment planning.

This possible classification has the potential advantage of assessing trismus resulting from factors other than mucosal fibrosis, its incidence in edentulous mouth and when clinical assessment is not possible due to severe trismus.

The term fibrosis is used to indicate various fibrotic reactions involved in OSMF, such as submucosal fibrosis, mucosal scarring and muscular fibrosis. As the histopathological evaluation of all the involved oral surfaces is not possible for grading OSMF, we used the existing clinical parameters ${ }^{19}$ which are indicative of the clinical severity of tissue fibrosis.

The malignant transformation component assesses the suspicious lesion itself, including possible dysplasia and considers when lesions cannot be assessed due to lack of accessibility and visibility. Including any dysplasia further allows categorising it as low and high risk lesion as recommended by the WHO (2017). ${ }^{30}$ The TFM classification helps in systematic categorizing the information, recording data, proper communication, obtaining prognostic information and also to make it easy to understand the disease characteristics which can be easily applied by the trainees and clinicians.

Putting together all of our data from the classification, we have developed a three tier staging scheme (TFM staging) which allows for differentiation between medical, surgical and malignant disease therapy (Table 5). For TFM staging, it is mandatory that the patient should at least have stage 1 fibrosis feature $\left(\mathrm{F}_{1}\right)$ and the patients with no clinical fibrosis $\left(\mathrm{F}_{0}\right)$ are not eligible for TFM staging. In cases where the assessment is not possible $\left(F_{X}, M_{X}\right)$, surgical evaluation under general anaesthesia is recommended before using any TFM staging is made. Though the endoscopic examination of the oral cavity may aid in the evaluation of OSMF in 
cases of sever trismus, surgical fibrotomy to open the mouth should always be considered best practice.$^{24,30}$ Any suspicious lesions $\left(\mathrm{M}_{\mathrm{Q}}\right)$ or associated potentially malignant disorders $\left(\mathrm{M}_{\mathrm{P}}\right)$ should be subjected to histopathology before considering TFM staging.

\section{CONCLUSION:}

The complex properties of OSMF including multiple sites with diffuse borders, diverse clinical features, and associated trismus pose a clinicopathological challenge for a systematic classification and staging system. ${ }^{2,28,29}$ The present study has found that the different components associated with the structural progression of OSMF are independent of each other and also the architectural alteration of tissue may not be consistent throughout the oral cavity. Thus with current staging classifications there is a potential risk of documenting incomplete information, repetition at different stages and incorrect disease interpretation. We suggest that the proposed classification scheme describes the disease severity of the independent components separately such that the significance of each is meaningfully conveyed to the clinician. The staging may also effectively predict the risk of potential malignant change. Further work is needed to evaluate and formally validate this proposed classification more fully.

\section{ETHICS STATEMENT}

Approval granted by the Institutional research ethical committee (Human) of Navodaya medical college and Hospital Raichur

\section{FUNDING}

None

\section{CONFLICT OF INTEREST}

None

This article is protected by copyright. All rights reserved. 


\section{REFERENCES:}

1. Arakeri G, Rai KK, Hunasgi S, Merkx MAW, Gao S, Brennan PA. Oral submucous fibrosis: An update on current theories of pathogenesis. J Oral Pathol Med. 2017; 46:406-412.

2. More CB, Das S, Patel H, Adalja C, Kamatchi V, Venkatesh R. Proposed clinical classification for oral submucous fibrosis. Oral Oncol. 2012; 48:200-2.

3. Richa, Swain N, Vibha, Gopal Ray J, Rao S. Comment on the article "Proposed clinical classification for oral submucous fibrosis" by Chandramani B. More et al. Oral Oncol. 2012;48(3):290.

4. Sheshaprasad R, Hebbar PB, Pai A. Suggested modification for the proposed clinical classification on OSMF. Oral Oncol. 2013; 49:e4.

5. Arakeri G, Brennan PA. Oral submucous fibrosis: an overview of the aetiology, pathogenesis, classification, and principles of management. $\mathrm{Br} \mathrm{J}$ Oral Maxillofac Surg. 2013; 51:587-93.

6. Ranganathan K, Mishra G. An overview of classification schemes for oral submucous fibrosis. J Oral Maxillofac Pathol 2006;10:55-8.53.

7. Rajendran R. Oral submucous fibrosis. J Oral Maxillofac Pathol. 2003;7:1-4.12.

8. Pindborg JJ. Oral submucous fibrosis: a review. Ann Acad Med Singapore. 1989;18:603-7.

9. Pindborg JJ, Sirsat SM. Oral submucous fibrosis. Oral Surg Oral MedOral Pathol. $1966 ; 22: 764-79$.

10. Utsunomiya H, Tilakaratne WM, Oshiro K, et al. Extracellular matrix remodeling in oral submucous fibrosis: its stage-specific modes revealed by immunohistochemistry and in situ hybridization. J Oral Pathol Med. 2005;34:498-507.

This article is protected by copyright. All rights reserved. 
11. Wahi PN, Luthra UK, Kapur VL. Submucous fibrosis of the oral cavity. Histomorphological studies. Br J Cancer. 1966;20:676-87.54.

12. Ahuja SS, Agrawal GD. Submucous fibrosis of the oral mucosa. J Oral Med $1971 ; 26: 35-6$.

13. Kerr AR, Warnakulasuriya S, Mighell AJ, et al. A systematic review of medical interventions for oral submucous fibrosis and future research opportunities. Oral Dis. 2011 Apr;17 Suppl 1:42-57.

14. Gupta DS, Gupta MK, Golhar BL. Oral submucous fibrosis-clinical study and management of physiofibrolysis (MWD). J Indian Dent Assoc. 1980;52:375-8.

15. Mathur RM, Jha T. Normal oral flexibility—a guideline for OSMF. J Indian Dent Assoc 1993;64:139-43.

16. Lai DR, Chen HR, Lin LM, Huang YL, Tsai CC. Clinical evaluation of different treatment methods for oral submucous fibrosis. A 10-yearexperience with 150 cases. J Oral Pathol Med 1995;24:402-6.

17. Haider SM, Merchant AT, Fikree FF, Rahbar MH. Clinical and functional staging of oral submucous fibrosis. J Oral Maxillofac Surg 2000;38:12-5.

18. Ranganathan K, Devi U, Joshua E, Bhardwaj A, Rooban T, ViswanathanR. Mouth opening, cheek flexibility and tongue protrusion parameters of 800 normal patients in Chennai, South India - a baseline study to enable assessment of alterations in oral submucous fibrosis. J Ind Dent Assoc2001;72:78-80.

19. Khanna JN, Andrade NN. Oral submucous fibrosis: a new concept in surgical management. Report of 100 cases. Int J Oral Maxillofac Surg. 1995;24:433-9.42.

20. Oken MM, Creech RH, Tormey DC, et al. Toxicity and response criteria of the Eastern Cooperative Oncology Group. Am J Clin Oncol. 1982;5: 649e655.

This article is protected by copyright. All rights reserved. 
21. McHugh ML. Interrater reliability: the kappa statistic. Biochem Med (Zagreb). 2012;22:276-82

22. National Committee on Vital Health and Statistics. Classifying and reporting vital statistics. Available at: https://www.ncvhs.hhs.gov/wpcontent/uploads/2017/08/010617rp.pdf. Accessed 12 Jan 2018.

23. Chourasia NR, Borle RM, Vastani A. Concomitant Association of Oral Submucous Fibrosis and Oral Squamous Cell Carcinoma and Incidence of Malignant Transformation of Oral Submucous Fibrosis in a Population of Central India: A Retrospective Study. J Maxillofac Oral Surg. 2015;14:902-6.

24. Jayasinghe LA, Peiris PM, Tilakaratne WM, et al. Clinically malignant exophytic lesions in the background of oral submucous fibrosis: report of five cases. Oral Surg Oral Med Oral Pathol Oral Radiol. 2016 ;122:210-5.

25. Liu B, Shen M, Xiong J, et al. Synergistic effects of betel quid chewing, tobacco use (in the form of cigarette smoking), and alcohol consumption on the risk of malignant transformation of oral submucous fibrosis (OSF): a case-control study in Hunan Province, China. Oral Surg Oral Med Oral Pathol Oral Radiol. 2015;120(3):337-45

26. Gadbail AR, Chaudhary M, Gawande M, et al. Oral squamous cell carcinoma in the background of oral submucous fibrosis is a distinct clinicopathological entity with better prognosis. J Oral Pathol Med. 2017;46:448-453.

27. Chaturvedi P, Vaishampayan SS, Nair S, et al. Oral squamous cell carcinoma arising in background of oral submucous fibrosis: a clinicopathologically distinct disease. Head Neck. 2013;35:1404-9.

28. Arakeri G, Colbert S, Patil SG, Hale B, Merkx MA, Brennan PA. Salivary pooling: is it specific to particular regions in oral submucous fibrosis? Br J Oral Maxillofac Surg. $2015 ; 53: 275-8$

This article is protected by copyright. All rights reserved. 
29. Agarwal RK, Hebbale M, Mhapuskar A, Tepan M.Correlation of ultrasonographic measurements, histopathological grading, and clinical staging in oral submucous fibrosis. Indian J Dent Res. 2017; 28:476-481.

30. Reibel J, Gale N, Hile J, et al. Oral potential malignant disorders and oral epithelial dysplasia. In: el-Naggar AK, Chan JKC, Grandis JR, Takata T, Slootweg PJ, editors. WHO classification of tumours of the head and neck. 4th ed. Lyon: IARC Press, 2017; pp:112-113

\section{FIGURE AND TABLE LEGENDS}

\section{Figure 1}

(A) Significant OSMF of pterygomandibular raphe, soft palate and uvula without affecting mouth opening (B) Buccally erupted maxillary third molar impingement causing an ulcerative lesion affecting the efficiency of mouth opening in OSMF (C) Malignant changes in early stage OSMF

Table 1 Functional and clinical features of oral submucous fibrosis as proposed by Khanna and Andrade ${ }^{19}$

Table 2 Histological features of oral submucous fibrosis as proposed by Khanna and Andrade ${ }^{19}$

Table 3 Cross-tabulation of bilateral biopsy grading

Table 4 Parameters of TFM classification

Table 5 Proposed TFM staging of oral submucous fibrosis

This article is protected by copyright. All rights reserved. 
Table 1: Functional and clinical features of oral submucous fibrosis as proposed by Khanna and Andrade $^{19}$

\begin{tabular}{|c|c|c|}
\hline Stage & Functional staging & Clinical staging \\
\hline Stage 1 & $\begin{array}{l}\text { Interincisal } \\
\text { openings } \\
\text { of } 35 \mathrm{~mm} \text { and } \\
\text { above }\end{array}$ & $\begin{array}{l}\text { - } \quad \text { Burning sensation in the mouth, } \\
\text { - } \quad \text { Acute ulceration and recurrent } \\
\text { stomatitis } \\
\text { - } \quad \text { No associated mouth opening limitation }\end{array}$ \\
\hline Stage 2 & $\begin{array}{l}\text { Interincisal } \\
\text { openings } \\
\text { of } 26-35 \mathrm{~mm}\end{array}$ & $\begin{array}{l}\text { - } \quad \text { Mottled and marble-like buccal mucosa } \\
\text { - } \quad \text { Dense, pale, depigmented fibrosed } \\
\text { areas alternated with pink normal mucosa } \\
\text { - } \quad \text { Occasional red erythroplakic patches } \\
\text { - } \quad \text { Widespread sheets of fibrosis }\end{array}$ \\
\hline Stage 3 & $\begin{array}{l}\text { Interincisal } \\
\text { opening } \\
\text { of } 15-25 \mathrm{~mm}\end{array}$ & $\begin{array}{l}\text { Pale buccal mucosa firmly attached to } \\
\text { the underlying tissues } \\
\text { - Palpable vertical fibrous bands in the } \\
\text { premolar area } \\
\text { - Unable to blow out cheeks and whistle } \\
\text { - In the soft palate, the fibrous bands } \\
\text { were seen to radiate from the } \\
\text { pterygomandibular raphe or the anterior faucial } \\
\text { pillar in a scar-like appearance } \\
\text { - The lips may be affected with atrophy } \\
\text { of the vermilion border }\end{array}$ \\
\hline $\begin{array}{l}\text { Stage } 4 \\
\text { (4a and } \\
4 b)\end{array}$ & $\begin{array}{l}\text { Interincisal } \\
\text { opening } \\
\text { of } 15 \mathrm{~mm} \text { and } \\
\text { below }\end{array}$ & $\begin{array}{l}\text { - Thickened, shortened, and firm fauces, } \\
\text { with the tonsils compressed between the } \\
\text { fibrosed pillars } \\
\text { - } \\
\text { shrunken, fibrous bud uvula } \\
\text { - Narrowed isthmus, presence of circular } \\
\text { band around entire lip and mouth } \\
\text { - } \\
\text { tongue movement, diffuse papillary atrophy } \\
\text { - } \quad \text { Atrophy of the vermilion border. } \\
\text { - } \quad \text { Premalignant and malignant changes }\end{array}$ \\
\hline
\end{tabular}

This article is protected by copyright. All rights reserved. 
Table 2: Histological features of oral submucous fibrosis as proposed by Khanna and Andrade ${ }^{19}$

\begin{tabular}{|c|c|}
\hline Grade & Histopathology grading \\
\hline 1 & $\begin{array}{l}\text { - } \\
\text { - } \\
\text { - } \\
\text { Dine filated and congested blood vessels } \\
\text { - } \quad \text { Inflammatory cells mainly consisting of polymorphonuclear leukocytes with few } \\
\text { eosinophils } \\
\text { - } \quad \text { Normal, nonkeratinized epithelium with occasionally some hyperplasia }\end{array}$ \\
\hline II & $\begin{array}{l}\text { - } \\
\text { - } \\
\text { - } \\
\text { - } \\
\text { Dilated and congested butial hyalinization } \\
\text { - } \quad \text { Inflammaterate number of young fibroblasts } \\
\text { eosinophils and occasional plasma cells } \\
\text { - } \quad \text { Flattening or shortening of epithelial rete-pegs with varying degree of } \\
\text { keratinization }\end{array}$ \\
\hline III & $\begin{array}{l}\text { - } \quad \text { Juxta-epithelial hyalinization } \\
\text { - } \quad \text { Faintly discernible thickened collagen bundles separated by very slight, residual } \\
\text { edema } \\
\text { - } \quad \text { Constricted blood vessels } \\
\text { - } \quad \text { Mature fibroblasts with scanty cytoplasm and spindle-shaped nuclei } \\
\text { - } \quad \text { Inflammatory exudates consisting of lymphocytes and plasma cells } \\
\text { - } \\
\text { - } \\
\text { - }\end{array}$ \\
\hline $\begin{array}{c}\text { IV } \\
\text { (IV a and IV b) }\end{array}$ & $\begin{array}{l}\text { - } \\
\text { - } \\
\text { - } \\
\text { - } \\
\text { - } \\
\text { - } \\
\text { - } \\
\text { - } \\
\text { - } \\
\text { - }\end{array}$ \\
\hline
\end{tabular}

This article is protected by copyright. All rights reserved. 
Table 3 Cross-tabulation of bilateral biopsy grading

\begin{tabular}{|l|l|l|l|l|}
\hline \multirow{2}{*}{$\begin{array}{l}\text { Biopsy grading } \\
\text { right buccal } \\
\text { mucosa }\end{array}$} & \multicolumn{4}{|l|}{ Histopathological grading left buccal mucosa } \\
\cline { 2 - 5 } & Grade 1 & Grade 2 & Grade 3 & Grade 4 \\
\hline Grade 1 & $\mathbf{0}$ & 6 & 2 & 0 \\
Grade 2 & 8 & $\mathbf{0}$ & 0 & 0 \\
Grade 3 & 6 & 3 & $\mathbf{0}$ & 0 \\
Grade 4 & 0 & 0 & 0 & $\mathbf{0}$ \\
\hline
\end{tabular}

This article is protected by copyright. All rights reserved. 


\begin{tabular}{|c|c|c|}
\hline \multicolumn{3}{|c|}{ Trismus (T) } \\
\hline $\mathbf{T}_{\mathbf{X}}$ & \multicolumn{2}{|r|}{$\begin{array}{l}\text { Trismus cannot be assessed due to presence of confounding factors such as tooth } \\
\text { impingement, Temporomandibular join disorders (TMDs), infection etc }\end{array}$} \\
\hline $\mathbf{T}_{\mathbf{0}}$ & \multicolumn{2}{|r|}{ Interincisal distance of more than $36 \mathrm{~mm}$} \\
\hline $\mathbf{T}_{1}$ & \multicolumn{2}{|c|}{ Interincisal distance of 26 to $35 \mathrm{~mm}$} \\
\hline $\mathbf{T}_{2}$ & \multicolumn{2}{|c|}{ Interincisal distance of 15 to $25 \mathrm{~mm}$} \\
\hline $\mathbf{T}_{\mathbf{3}}$ & \multicolumn{2}{|r|}{ Interincisal distance of less than $15 \mathrm{~mm}$} \\
\hline \multirow[t]{5}{*}{$\mathbf{T}_{\mathbf{E}}$} & \multicolumn{2}{|r|}{ Edentulous (E) state due to either complete or partial loss of anterior teeth } \\
\hline & $\mathbf{T}_{\mathbf{E 0}}$ & Anterior free space after maximum mouth opening more than $41 \mathrm{~mm}$ \\
\hline & $\mathbf{T}_{\mathbf{E} 1}$ & Anterior free space after maximum mouth opening of 36 to $40 \mathrm{~mm}$ \\
\hline & $\mathbf{T}_{\mathbf{E} 2}$ & Anterior free space after maximum mouth opening of 25 to $35 \mathrm{~mm}$ \\
\hline & $\mathbf{T}_{\mathbf{E 3}}$ & Anterior free space after maximum mouth opening of less than $25 \mathrm{~mm}$ \\
\hline \multicolumn{3}{|c|}{ Fibrosis (F) } \\
\hline $\mathbf{F}_{\mathbf{0}}$ & \multicolumn{2}{|c|}{ No signs of fibrosis } \\
\hline $\mathbf{F}_{\mathbf{X}}$ & \multicolumn{2}{|r|}{ Fibrosis cannot be assessed due to severe trismus } \\
\hline $\mathbf{F}_{1}$ & \multicolumn{2}{|r|}{$\begin{array}{l}\text { Burning sensation in the mouth and/or blanching of oral mucosa and/or acute } \\
\text { ulceration and/or recurrent stomatitis }\end{array}$} \\
\hline $\mathbf{F}_{2}$ & \multicolumn{2}{|r|}{$\begin{array}{l}\text { Mottled and marble like oral mucosa, dense, pale, depigmented fibrosed areas } \\
\text { alternated with pink normal mucosa, widespread sheets of fibrosis (palpable } \\
\text { fibrous bands) involving labial and/or buccal mucosa and/or oropharynx }\end{array}$} \\
\hline $\mathbf{F}_{3}$ & \multicolumn{2}{|r|}{$\begin{array}{l}\text { Pale oral mucosa firmly attached to underlying tissues, palpable vertical fibrous } \\
\text { bands at the buccal mucosa, in the soft palate-radiating fibrous bands from the } \\
\text { pterygomandibular raphe or the anterior faucial pillar in a scar-like appearance, } \\
\text { atrophy of the vermilion border, patient unable to blow out cheeks and whistle }\end{array}$} \\
\hline $\mathbf{F}_{4}$ & \multicolumn{2}{|r|}{$\begin{array}{l}\text { Thickened faucial pillars, shrunken -fibrous bud like small uvula, narrowed } \\
\text { isthmus, restricted tongue movement, diffuse papillary atrophy, palpable circular } \\
\text { fibrous band around entire mouth, obliquity of rima oris, vermilion border } \\
\text { atrophy }\end{array}$} \\
\hline \multicolumn{3}{|c|}{ Malignant Transformation (M ) } \\
\hline $\mathbf{M}_{\mathbf{0}}$ & \multicolumn{2}{|r|}{ No signs of malignant transformation } \\
\hline $\mathbf{M}_{\mathbf{X}}$ & \multicolumn{2}{|r|}{ Malignant transformation cannot be assessed due to severe trismus } \\
\hline $\mathbf{M}_{\mathbf{Q}}$ & \multicolumn{2}{|r|}{ Lesion in question } \\
\hline $\mathbf{M}_{\mathbf{P}}$ & \multicolumn{2}{|c|}{ Associated potentially malignant disorder } \\
\hline \multirow[t]{3}{*}{$\mathbf{M}_{1}$} & \multicolumn{2}{|c|}{ Histopathological evidence of dysplasia } \\
\hline & $\mathbf{M}_{1 \mathbf{a}}$ & Low -grade \\
\hline & $\mathbf{M}_{1 \mathrm{~b}}$ & High- grade \\
\hline $\mathbf{M}_{2}$ & \multicolumn{2}{|r|}{ Histopathological evidence of malignant transformation } \\
\hline
\end{tabular}

Table 4 Parameters of TFM classification

This article is protected by copyright. All rights reserved. 
Table 5 TFM staging of oral submucous fibrosis

\begin{tabular}{|l|l|}
\hline Stage & TFM classification \\
\hline Stage 1 (Medical Therapy) & $\mathrm{T}_{0-2 / \mathrm{E} 0-\mathrm{E} 2}$ or $\mathrm{F}_{1-2}, \mathrm{M}_{0,1 \mathrm{a}}$ \\
\hline Stage 2 (Surgical Therapy) & $\mathrm{T}_{2-3 / \mathrm{E} 2-\mathrm{E} 3}$ or $\mathrm{F}_{3-4}, \mathrm{M}_{0,1 \mathrm{~b}}$ \\
\hline Stage 3 ( Neoplastic disease therapy ) & Any $\mathrm{T}, \mathrm{F}_{1-4}, \mathrm{M}_{2}$ \\
\hline
\end{tabular}
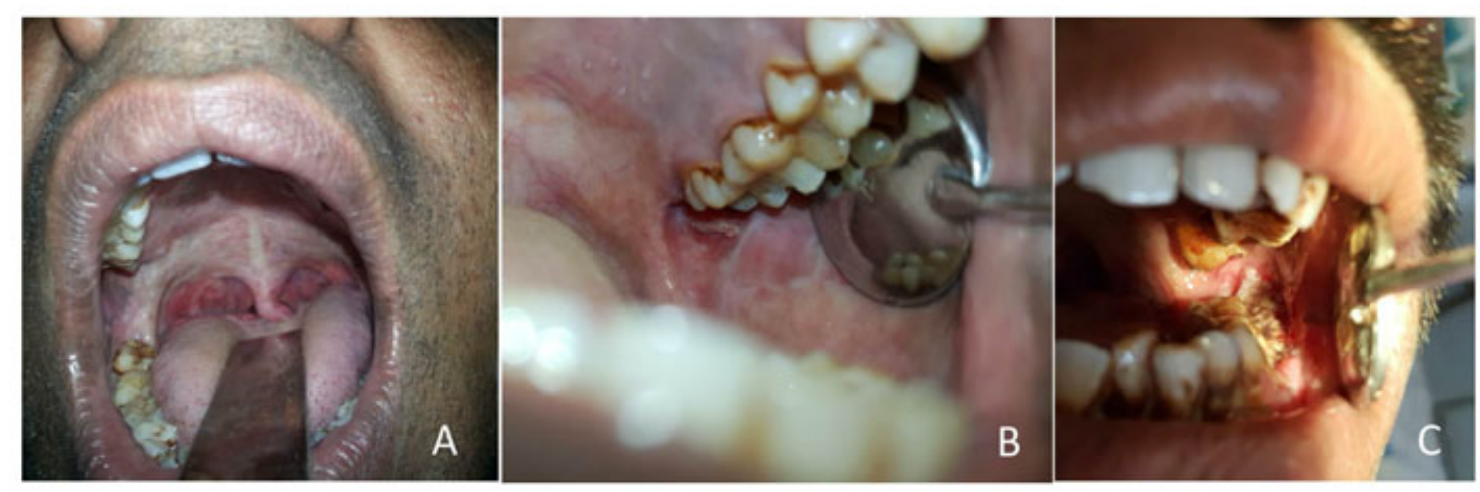